

\section{DISCLAIMER}

This report was prepared as an account of work sponsored by an agency of the United States Government. Neither the United States Government nor any agency Thereof, nor any of their employees, makes any warranty, express or implied, or assumes any legal liability or responsibility for the accuracy, completeness, or usefulness of any information, apparatus, product, or process disclosed, or represents that its use would not infringe privately owned rights. Reference herein to any specific commercial product, process, or service by trade name, trademark, manufacturer, or otherwise does not necessarily constitute or imply its endorsement, recommendation, or favoring by the United States Government or any agency thereof. The views and opinions of authors expressed herein do not necessarily state or reflect those of the United States Government or any agency thereof. 


\section{DISCLAIMER}

Portions of this document may be illegible in electronic image products. Images are produced from the best available original document. 


\title{
Ultrasonic Inspection of the Strength Member Weld of Transit and Pioneer Heat Sources
}

\author{
W. A. Dudley \\ Issued: May 1, 1975
}

This report wat price

sponsored by was prepared as an account of work

the United the United States Government of work

Research and States nor the United States. Neither

their emplovelopment Administration Energy

subcontractors, nor any of their, nor any of

warranty, or their emploir contractors,

liability, express or implied, or ass, makes any

or usef or responsibility for the or assumes any any or usefulness of any inf for the accuracy, completenel process disclosed or ormation, apparatus, proteness infringe privately owned resents that its use wouct of inge privately owned rights.

\section{NOTICE}

This report was prepared as an account of work sponsored by the United States Government. Neither the United States nor the United States Energy Research and Development Administration, nor any of their employees, nor any of their contractors, subcontractors, or their employees, makes any warranty, express or implied, or assumes any legal llability or responsibility for the accuracy, completeness or usefulness of any information, apparatus, product or process disclosed or represents that its use would not infringe privately owned rights.

PRINTED IN THE UNITED STATES OF AMERICA

Available from

National Technical Information Service

U.S. Department of Commerce

5285 Port Royal Road

Springfield, Virginia 22161

Price: Printed Copy \$4.00; Microfiche $\$ 2.25$

\section{MONSANTO RESEARCH CORPORATION}

A Subsidiary of Monsanto Company

\section{MOUND LABORATORY}

Miamisburg, Ohio

operated for

\section{UNITED STATES ENERGY RESEARCH AND DEVELOPMENT ADMINISTRATION}

U.S. Government Contract No. AT-33-1-GEN-53 
ABSTRACT

A nondestructive technique was developed which allows ultrasonic inspection of the closure weld for the strength member component in plutonium238 radioisotopic heat sources. The advantage of the ultrasonic approach, over that of the more commonly used radiographic one, is the recognized superiority of ultrasonic testing for identifying lack-of-weld penetration (LOP) when accompanied by incomplete diffusion bonding. The ultrasonic technique, a transverse mode scan of the weld for detection of LOP, is primarily accomplished by use of a holding fixture which permits the vented heat source to be immersed into an inspection tank. The mechanical portion of the scanning system is a lathe modified with an inspection tank and a manipulator. This scanning system has been used in the past to inspect SNAP-27 heat sources. The analyzer-transducer combination used in the inspection is capable of detecting a channel type flaw with a side wall depth of $0.076 \mathrm{~mm}(0.003 \mathrm{in.})$ in a weld standard. 


\section{INTRODUCTION}

Ausillary power for long-term space applications, such as planetary flybys and navigational probes, requires energy sources that are reliable and compact. The auxillary power in the Transit and Pioneer programs was supplied by Radioisotopic Thermoelectric Generators (RTGs). The heart of the RTG is the encapsulated plutonium-238 radioisotopic heat source. The Pioneer heat source is schematically shown in Figure 1. The Transit heat source is similar to the Pioneer, but it is approximately $2.5 \mathrm{~cm}$ (1 in.) longer. The Transit source has a thermal output of $850 \mathrm{~W}$ while the Pioneer has a thermal output of $650 \mathrm{~W}$. The fuel is in the shape of disks made from molybdenum-coated plutonium dioxide particles which have been hot pressed under vacuum to form a dense composite. The fuel is confined in a triply-contained package which consists of 1) a Ta-10W liner which is compatible with the fuel, 2) T-111 strength member, and 3) a Pt-20Rh clad which protects the capsule from the generator environment. Special dome end vents, primarily designed to retain any particulate matter within the interior container, allow the release of helium gas generated from alpha decay of the plutonium-238 fuel.

Several nondestructive testing techniques were used to characterize weld. quality in the heat source. Ultrasonics was chosen to inspect for lackof-weld penetration (LOP). However, restrictive handing and fabrication procedures for heat sources limited this approach to the strength member stage of assembly. The strength member weld was considered acceptable when there was no ultrasonic indication of LOP, and ultrasonic inspection was used for detection of LOP only. Radiography, on the other hand, was used for detection of weld porosity, inclusions, etc.

\section{EQUIPMENT}

Description of Inspection System The basic mechanical system used for the ultrasonic inspection is shown in Figures 2 and 3 , and consists of a modified clausing metal lathe with tail stock and tool post removed. This system was built by Battelle Northwest and was most recently used to ultrasonically inspect SNAP-27 heat sources. Table 1 lists, in addition to the above basic test system, the remaining equipment used in conjunction with this inspection.

As shown in Figure 2, a tank has been fitted to the lathe and a carriage has been installed with a four-axis transducer manipulator. The lathe spindle has been fitted with a three jaw chuck, and both the tank and chuck were fabricated from stainless steel to resist corrosion. In addition, the rotational motion of the chuck and both the longitudinal and the transverse motions of the transducer manipulator have been synchronized 


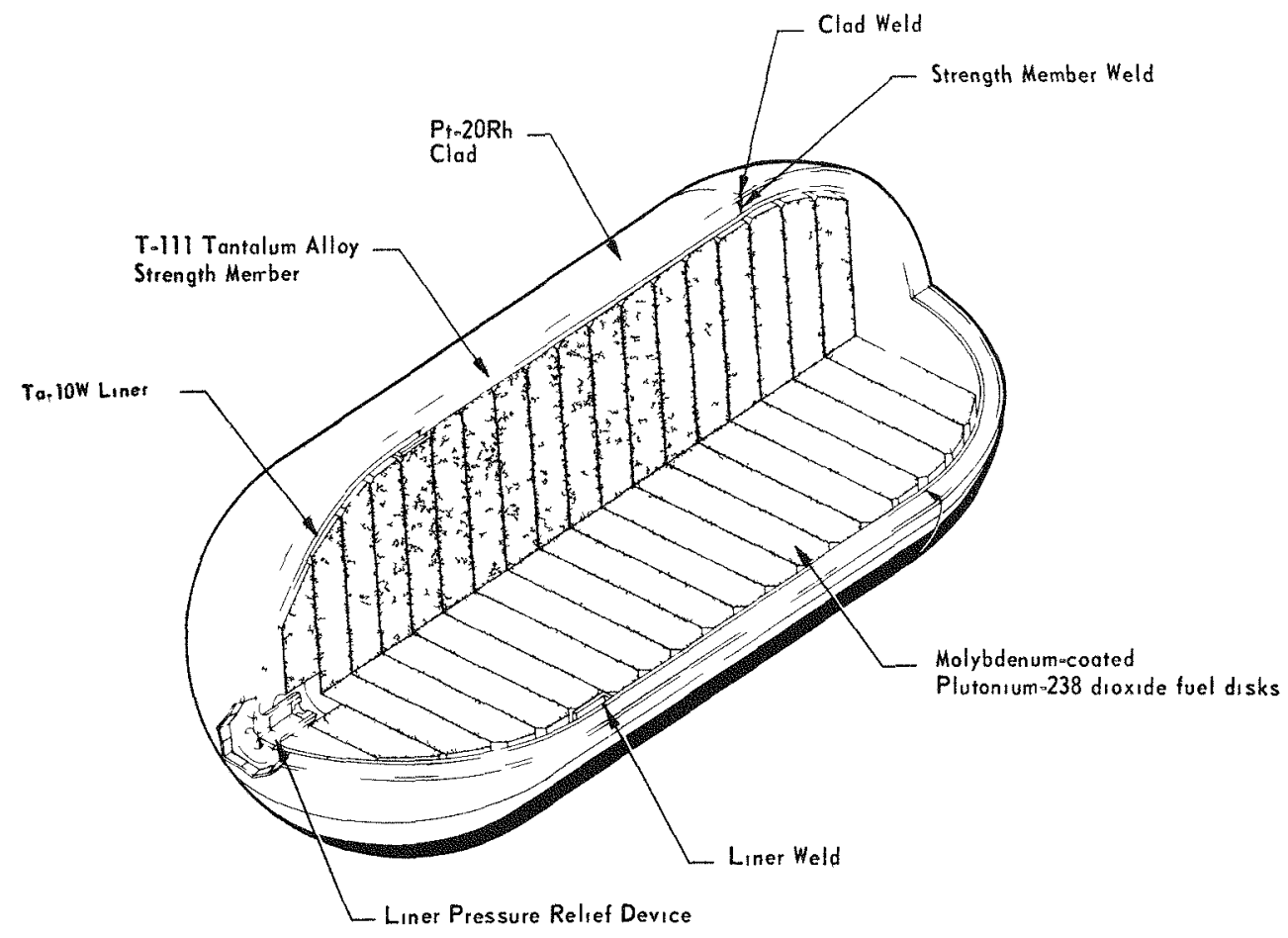

FIGURE 1 - AssembIy sketch for Pioneer heat source.

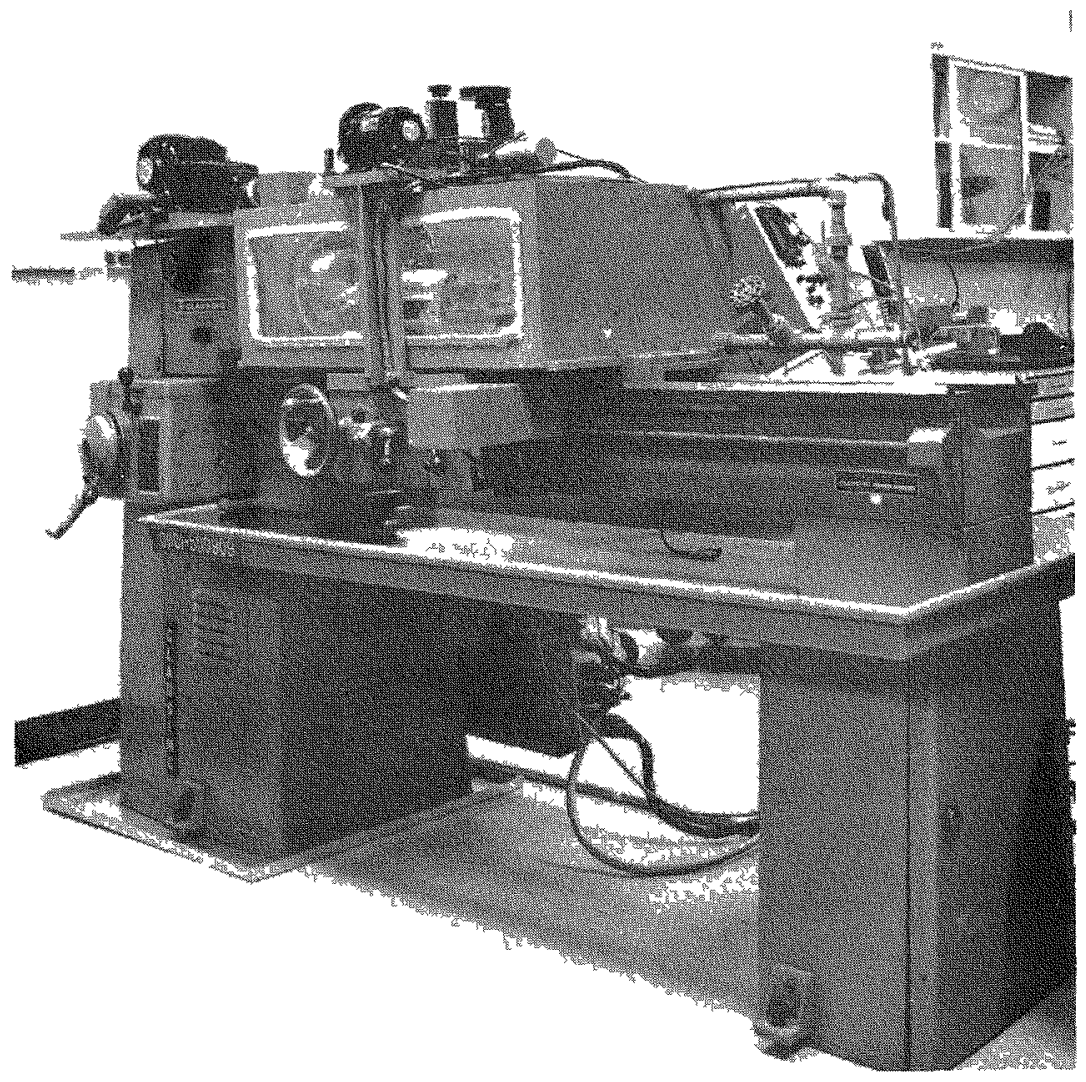

FIGURE 2 - Modified lathe. 


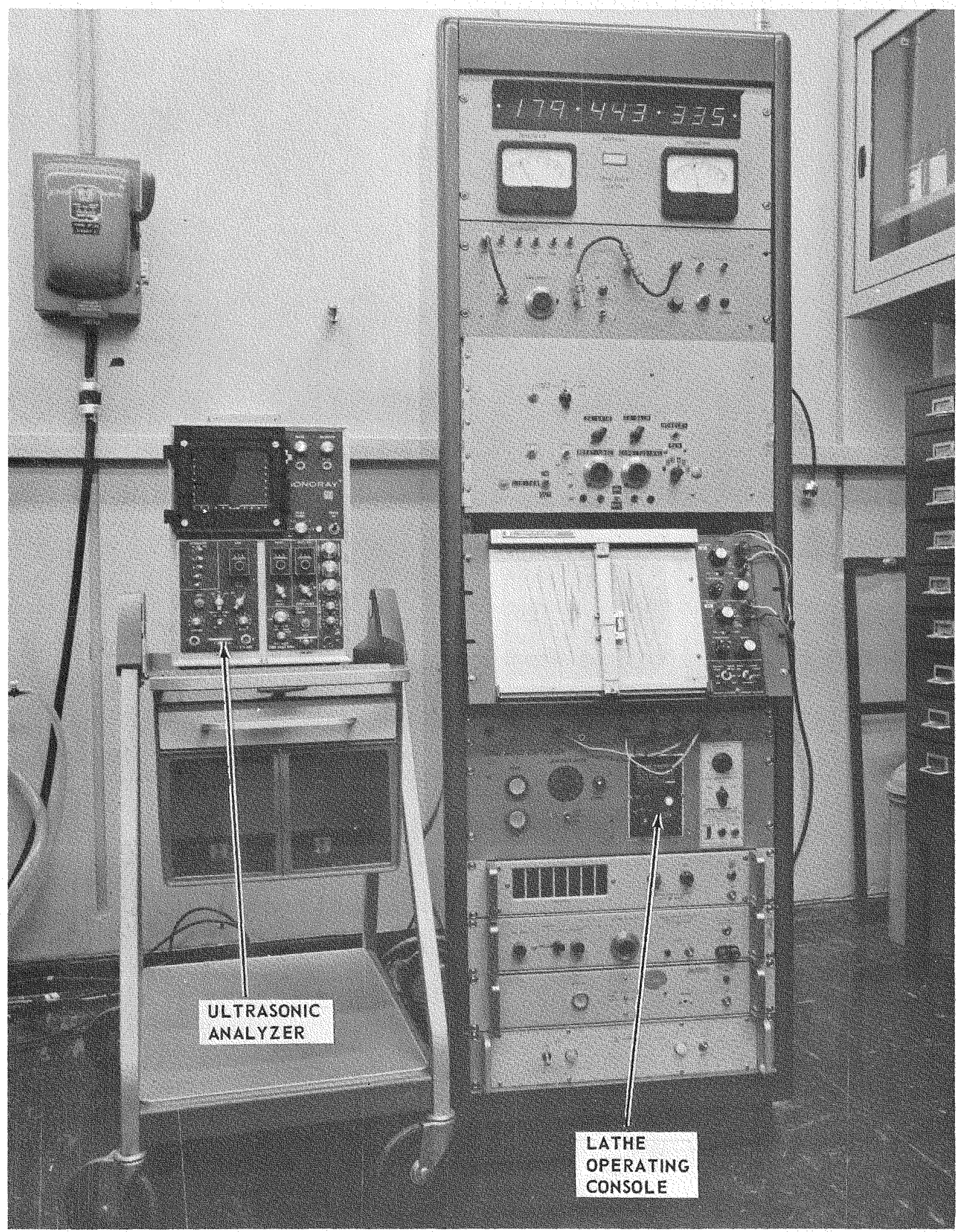

FIGURE 3 - Ultrasonic analyzer and lathe operating console. 
Table 1

EQUIPMENT LIST

Equipment or Component

Modified lathe inspection system

(BNWL-CC-1288)

Holding fixture (DWG. No. 4-9154)

Weld standard (Control Weld $S / N$ 006)

Tail stock support for handling fixture (DWG. No. 4-8896)

Ultrasonic analyzer (Bronson Sonoray, Model 600, Display with Model $623 \mathrm{P} / \mathrm{R}$ and Model 610 \% Time base or equivalent)

Transducer [Automated Industries, style $57 \mathrm{~A} 2765$ or equivalent ( $10 \mathrm{MHz}$; Focal Short, 1/4 in. diam, Lithium Sulphate)]

Recorder (Hewlett-Packard, Type 135, Moseley $X-Y$ Recorder or equivalent)
Corresponding Illustration

See Figures 2 and 3

See Figures 5,6 , and 7

See Figures 9 and 10

See Figure 7

See Figure 5

See Figures 6 and 7

See Figure 3

to motion translation devices. In turn, these translation devices simultaneously supply a signal voltage via interface circuitry to an $x-y$ recorder and position encoders.

Figure 3 shows the operating console for the modified lathe system and the commercial ultrasonic analyzer used in the inspection. The paper recording shown in Figure 3 typifies the inspection data obtained from a quality weld and represents an isometric display of the ultrasonic responses from that weld for two separate inspection passes. That is, as sketched in Figure 4, the weld is first scanned in a transverse direction starting from one side of the weld followed by a scan from the opposite side of the weld.

Sample Holding Fixture Figure 5 shows the holding fixture which was designed to adapt the strength member assembly to the modified lathe inspection system. This fixture permits the strength member to be rotated around its central axis while maintaining an o-ring seal against the dome end of the strength member assembly. The o-ring seal is necessary to prevent air or water from coming in contact with the two miniature vent holes during handling and inspection of the heat source. The vent holes, which are shown in Figure 4, have been designed into the heat source to allow the helium gas generated by alpha decay of the plutonium-238 fuel to escape. This gas venting provision is necessary to eliminate internal pressure buildup which if not relieved would significantly shorten the structural life of the heat source. Source degradation would also result if the o-ring seal of the holding fixture did not prevent water from getting into the interior of the strength member. 


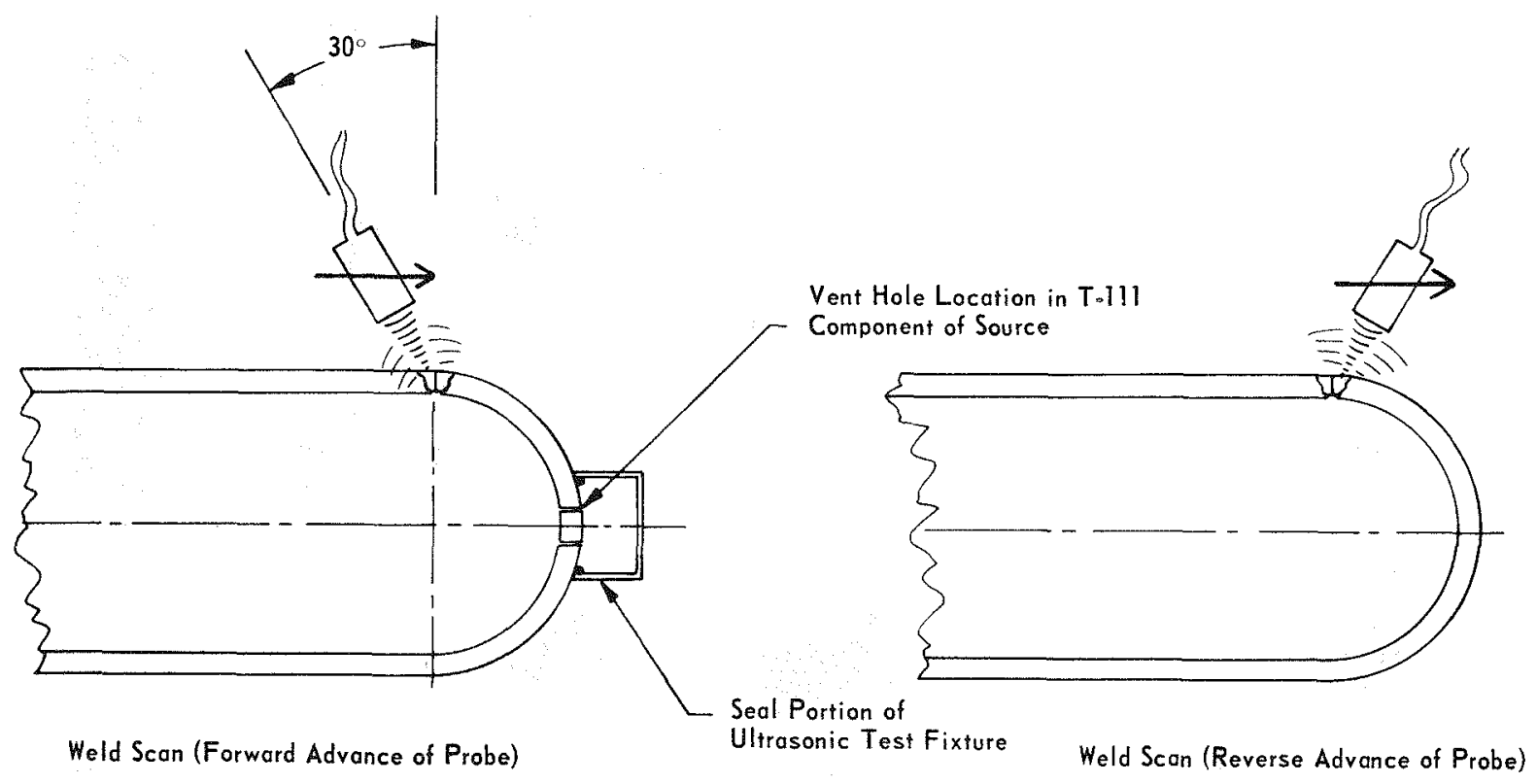

FIGURE 4 - sketch showing search unit alignment and direction of probe advance for respective scans of the weld.

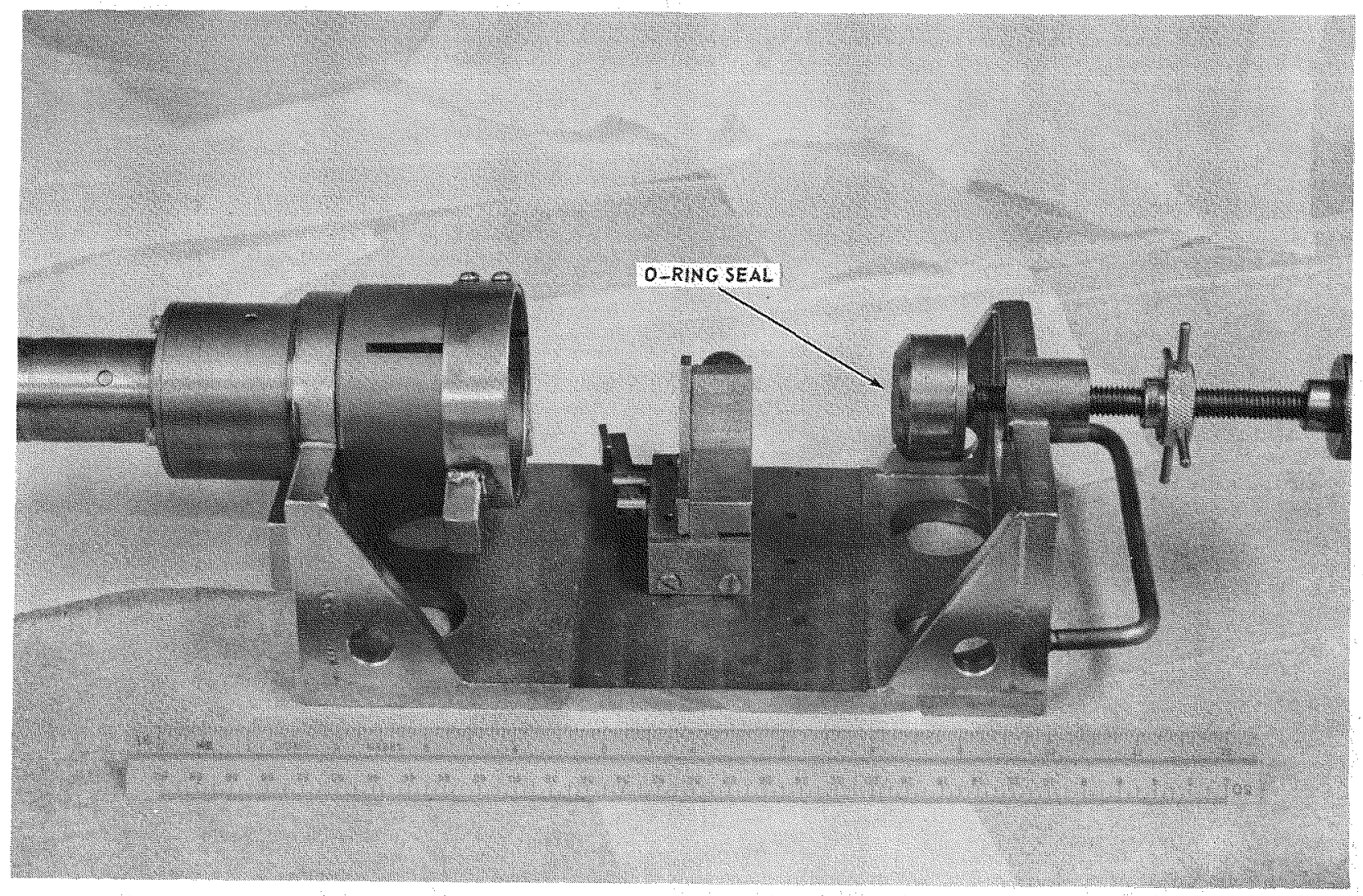

FIGURE 5 - HOIding fixture. 




FIGURE 6 - Photo of actual weld inspection. 
Miscellaneous Support Hardware Figure 6 is a photo taken during an actual weld inspection of a heat source. The heat source is immersed in the lathe tank and the water in the tank is maintained at room temperature by a coiled heat exchanger. The metal housing around the transducer, as shown in both Figures 6 and 10 , is a shroud through which the inspection liquid is separately pumped at ambient temperature from the periphery of the tank. The purpose of the forced flow of ambient water through the shroud is two-fold: (1) to reduce thermal gradients which cause nolse in the ultrasonic presentation, and (2) to eliminate surface bubbles which cause spurious echo responses.

Figure 7 shows the complete fixturing setup required to accomplish an inspection. The item fixtured in this figure is an aluminum mock-up of the pioneer heat source. The tail stock shown in this figure has two axes of linear motion to permit the central axis of the heat source to be aligned with the carriage motion of the scanning transducer. To keep the fixture itself from rotating, a post interfaces with a channel located on the body of the heat source fixture.

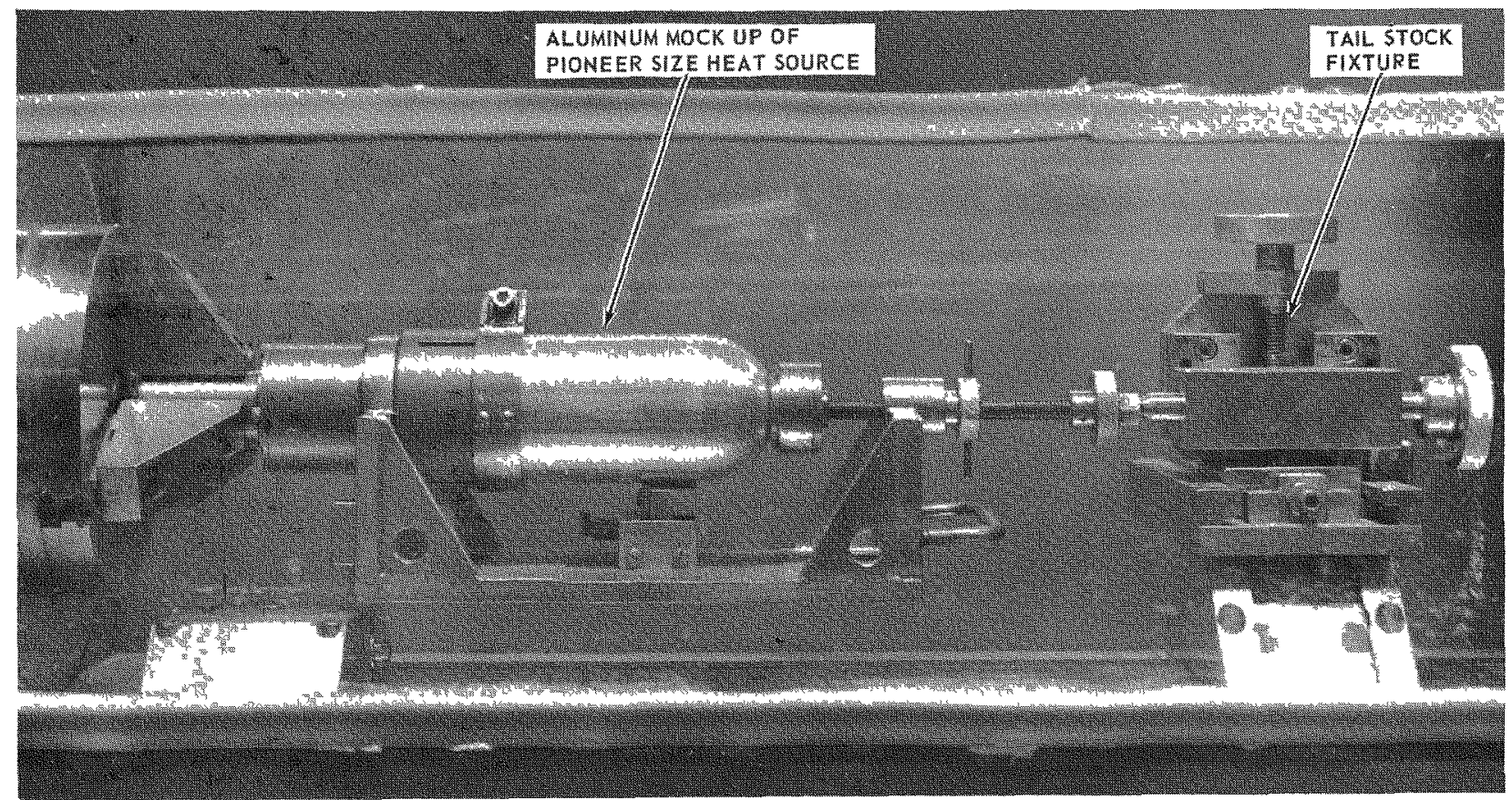

FIGURE 7 - Complete fixturing setup required to accomplish an inspection.

\section{EXPERIMENTAL}

Procedure (General) Ultrasonic inspection of the Transit or Pioneer strength member weld for LOP consists of an immersed shear mode scan of the entire circumferential length of the weld. Figure 1, an artist's sketch of the basic heat source assembly. shows the location of the plutonia fuel and the various containment layers. Figure 8 shows a detailed engineering sketch of the weld joint design of the strength member (TIG) weld. The shaded area of Figure 8 represents the region of 


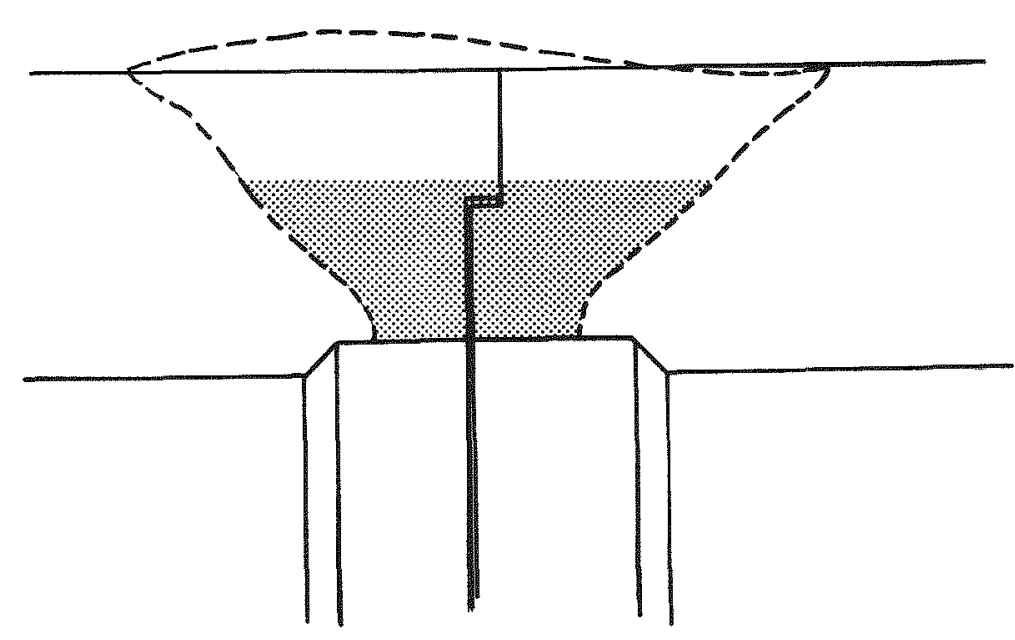

40X SIZE
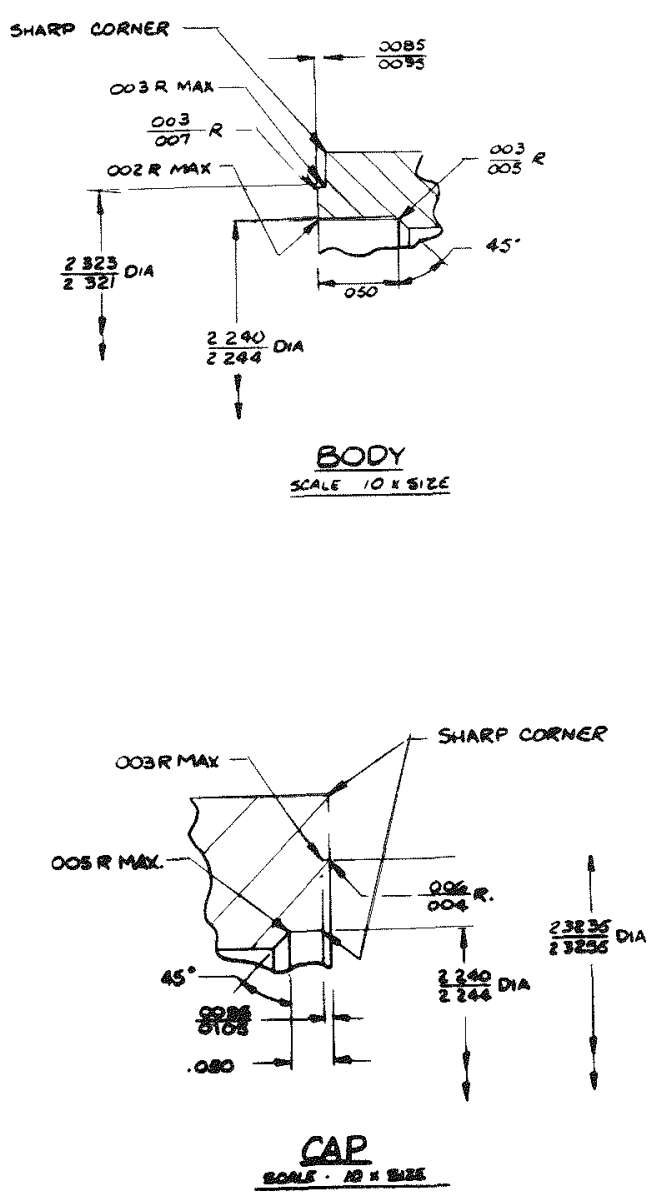

FIGURE 8 - Engineering sketch of weld joint design. 
the weld monitored during application of the ultrasonic inspection while the dotted line represents the resultant contour and extent of the heat affected zone typical of a quality weldment.

Description of the Ultrasonic Procedure After the strength member assembly is welded, the heat source is loaded into the ultrasonic test fixture. The fixtured source is then immediately transferred to a portable stainless steel drum filled with distilled water. The drum is equipped with a refrigeration unit which cools the distilled water. Next, the fixtured heat source is removed from the portable drum and rapidly immersed in the inspection tank. After securing the heat source fixture in the inspection system, the flow rate of the cooling coil is adjusted to maintain ambient temperature. The pump is then turned on to force water through the tubular device shrouding the transducer. After the above procedures have been completed, the transducer is manually aligned incident to the sources outside diametric surface at an angle of $30^{\circ}$ from normal to cause shear refraction at $45^{\circ}$. The transducer is then moved into position to detect the first pass reflection from the base corner of the weld step (the weld step is left intact and easily located). Then, the ultrasonic response from the base step corner is peaked by adjusting the length of the water path.

Once the transducer setup has been accomplished, the operation is switched to an automated scan. During the automated scan, the transducer is advanced parallel to the central axis of the heat source at a rate of 7.5 mils per source revolution. For alternate scan revolutions, the ultrasonic analyzer output is plotted on the $x-y$ recorder. To establish recorder indexing, it is necessary to record the ultrasonic data for alternate scans. When the weld region of interest has been scanned, the automated scan is interrupted; and the transducer is then set up to scan the weld from the opposite direction.

A flaw standard, shown in Figure 9, is used to "tune" the analyzer prior to an inspection. This standard was fabricated by cutting away almost all of the body of a welded strength member assembly and eloxing three channels of various depths into the center of the back surface of the weld joint. The standard does not require complex fixturing and is mounted in the inspection system as shown in Figure 10. The 2 mil deep eloxed slot is representative of the maximum depth of back surface openness allowed in an acceptable weld and is analogous to retainment of the machined radius of the base corner of the weld joint as shown in Figure 8. Ultrasonic responses from the weld which correlate for both scans and exceed by $50 \%$ the average signal strength obtained from the $2 \mathrm{mil}$ artificial flaw are considered cause for possible weld rejection. Ultrasonic detection of this degree of openness in a weld predicates the occurrence of one of two undesirable but acceptable weld conditions, namely, (a) just achieving full weld penetration, and (b) LOP accompanied by complete diffusion bonding. However in the event of a detected anomaly, the ultrasonic data would then be separately correlated with radiographic data to guard against misinterpretation resulting from unusual but acceptable weld back surface conditions. 

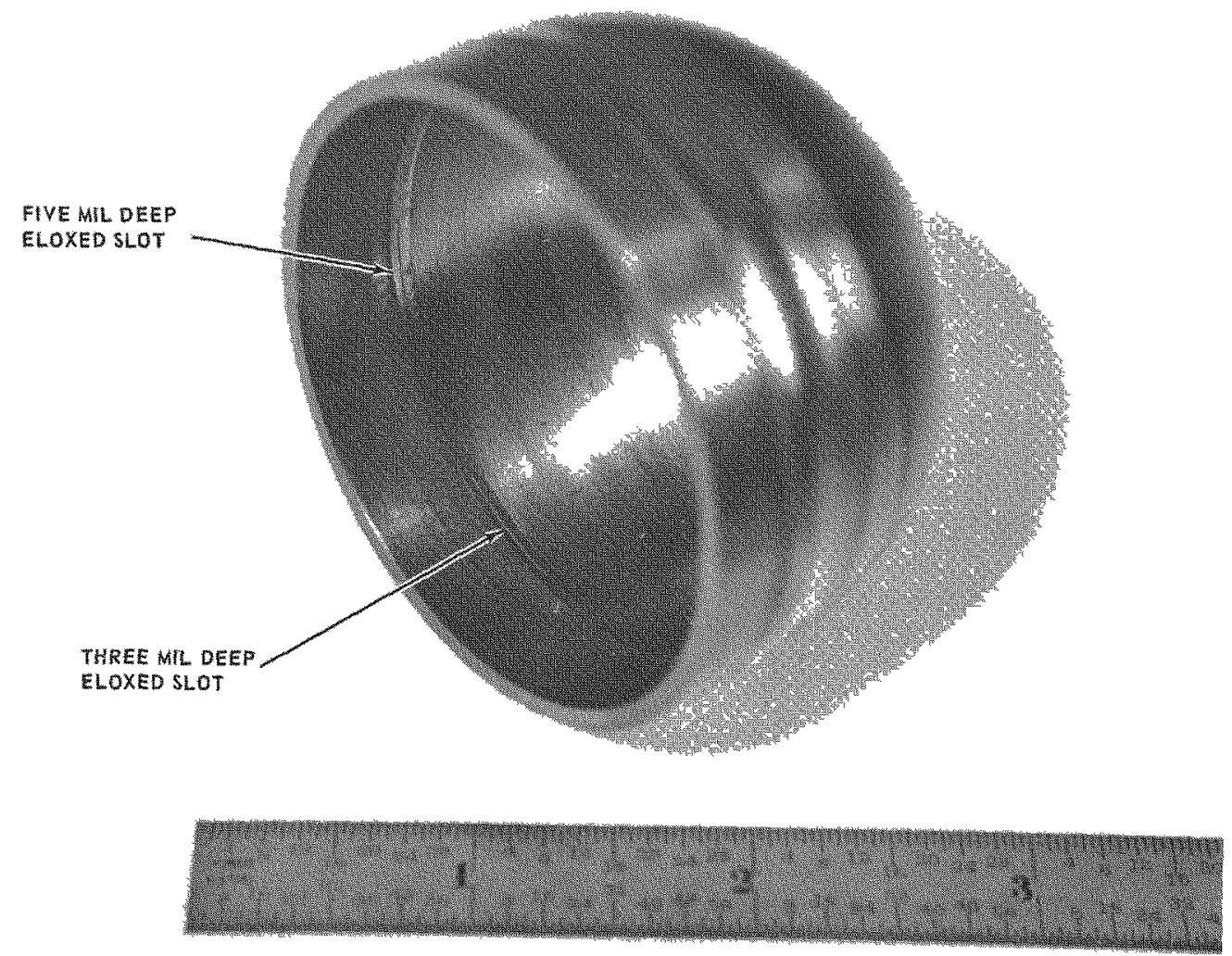

FIGURE 9 - FIaW standard.

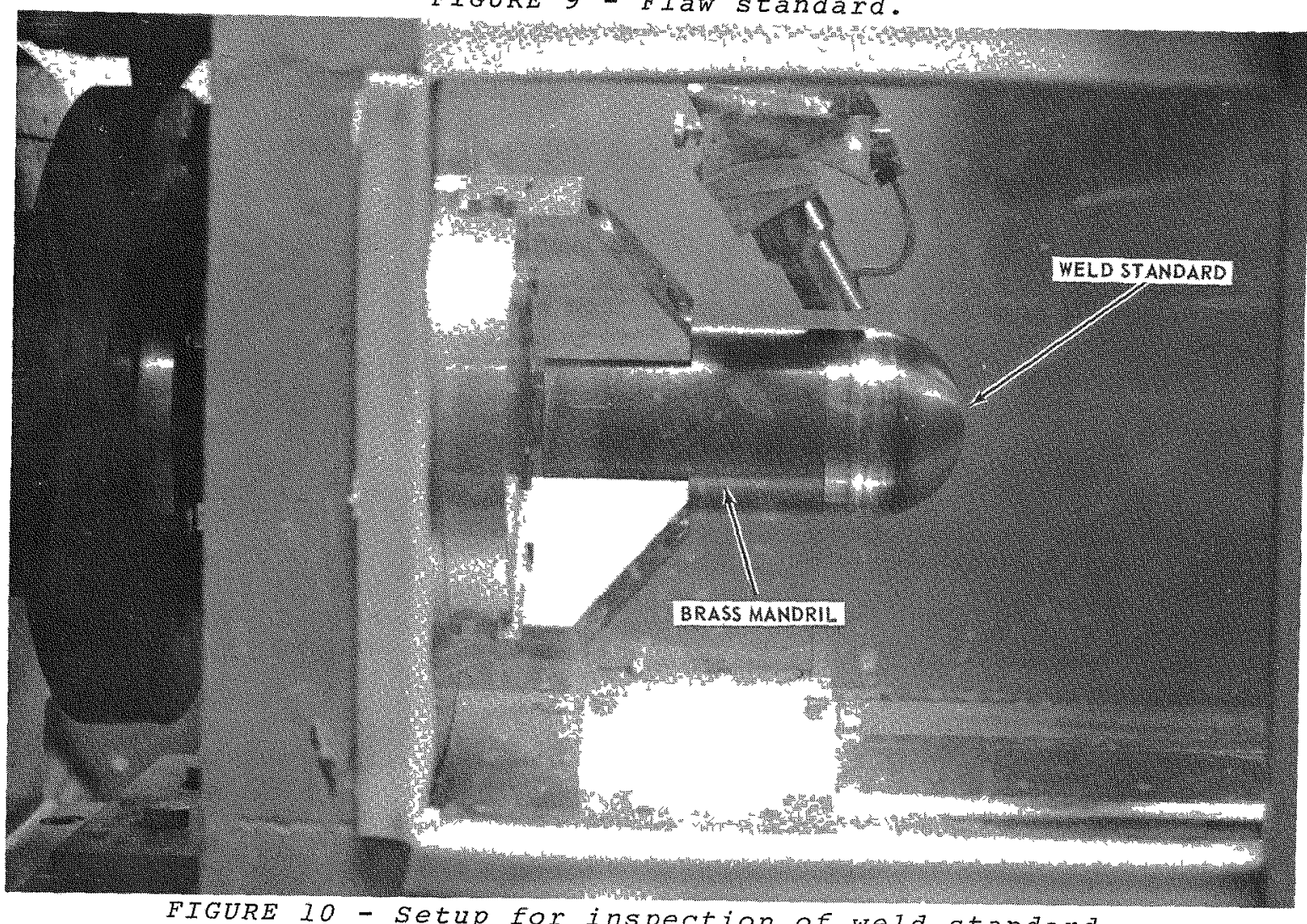

FIGURE 10 - setup for inspection of weld standard. 
Test Development Results The ability of this ultrasonic technique to detect LOP was assessed for application to "controlled" welds. Six sets of strength member components were used. Two sets were welded to exhibit LOP while two other sets were welded at full penetration and then used as ultrasonic standards. The remaining two sets were welded under conditions which caused weld surface porosity and cracking. Only LOP was detected by the ultrasonic technique, and subsequent metallographic examination of the control welds revealed that ultrasonic detection of LOP occurred only in the absence of complete diffusion bonding below the weld root. Radiography performed on the same units only implied the existence of LOP but these implications were not conclusive since the weld joints were mechanically tight.

What was initially sought for the LOP control weld were regions along the length of the weld line representing weld regions of full, 75\%, 50\%, and $25 \%$ weld penetration. What was actually achieved, as verified through destructive testing, were weld regions of full, full to $75 \%$, 50\%, and 40 to $25 \%$ of penetration, respectively. Figures 11 and 12 are photomicrographs of a control weld ( $\mathrm{S} / \mathrm{N}$ 003) in the $50 \%$ penetration region which has been cross sectioned and etched. These two figures represent, for both LOP control welds, the deepest weld penetration level for which ultrasonic detection of the "under-welded" condition was observed. At the 50\% penetration level, only weak ultrasonic responses were detected for the under-welded condition. Some large responses were occasionally obtained with all the control welds and to some extent with early production example welds. However, these large responses were shown to be related to weld joint incongruities being retained in an under-welded condition.

Examples of joint incongruities are excessive gapping, joint component mismatch, or a combination of both. However, hardware not meeting preweld design specifications in the above categories are eliminated from production usage by gaging and only occasional retainment of a minor mismatch condition has been observed in production units. An example of the joint mismatch condition is shown in Figures 11 and 12 . The signal strength of the ultrasonic response obtained from this specific mismatch condition reinforces the signal normally obtained from LOP.

The reason for the weak signal response associated with detectable LOP is clarified by comparative examination of the unwelded portion of the weld joint shown in Figures 11 and 12. In Figure 11, which shows an ultrasonically non-indicating (LOP) region at the 50\% weld penetration level, it is observed that the grain boundaries continuously cross the length of the unwelded portion of the joint, particularly near the joint base. However, in Figure 12, which shows an ultrasonically indicating (LOP) region at the same penetration level, it is observed that fewer grains cross the unwelded portion of the joint at its base region. The type of joint shown in Figure 11 is the result of complete diffusion bonding while that shown in Figure 12 is the result of incomplete diffusion bonding. In both examples, however, the unwelded portion of the respective joints are mechanically tight.

Overall, the signal strength of LOP, ultrasonically detected at the $50 \%$ level, is somewhere between the signal strength obtained for the 2 mil 


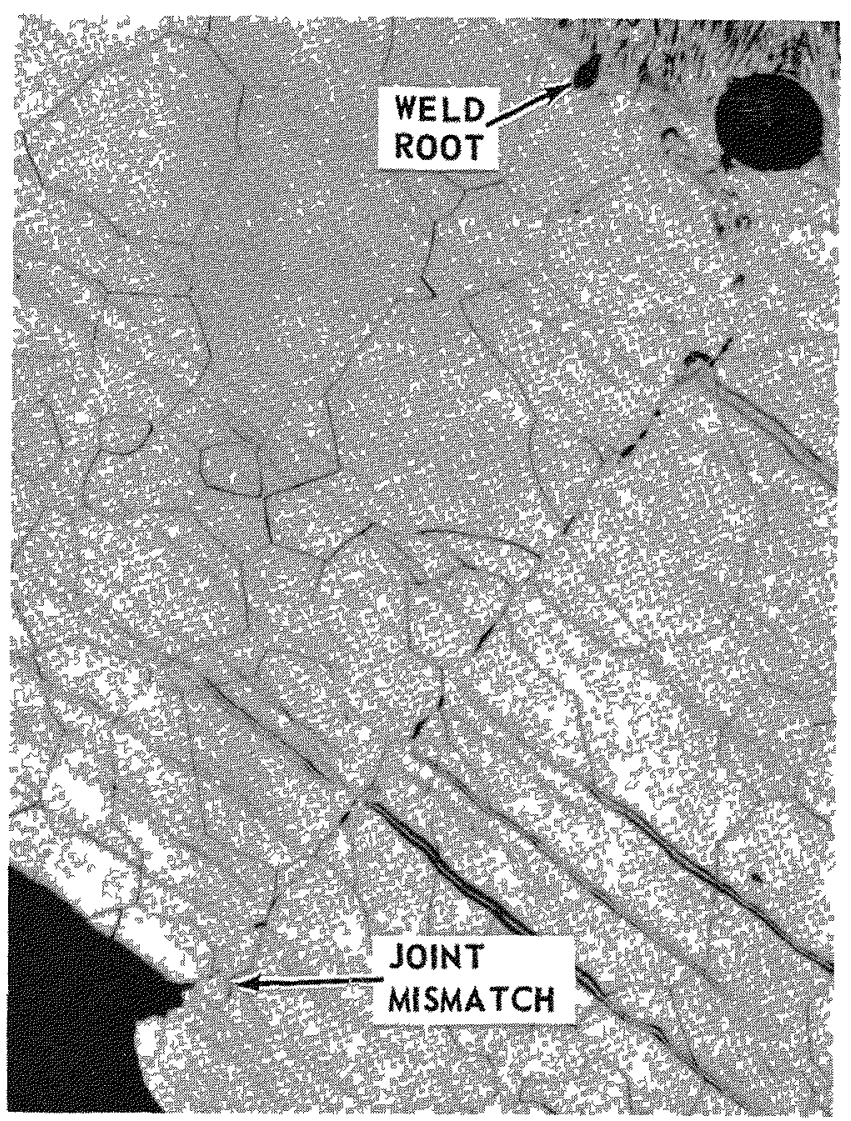

FIGURE II - Fifty percent weld penetration $(100 X)$.

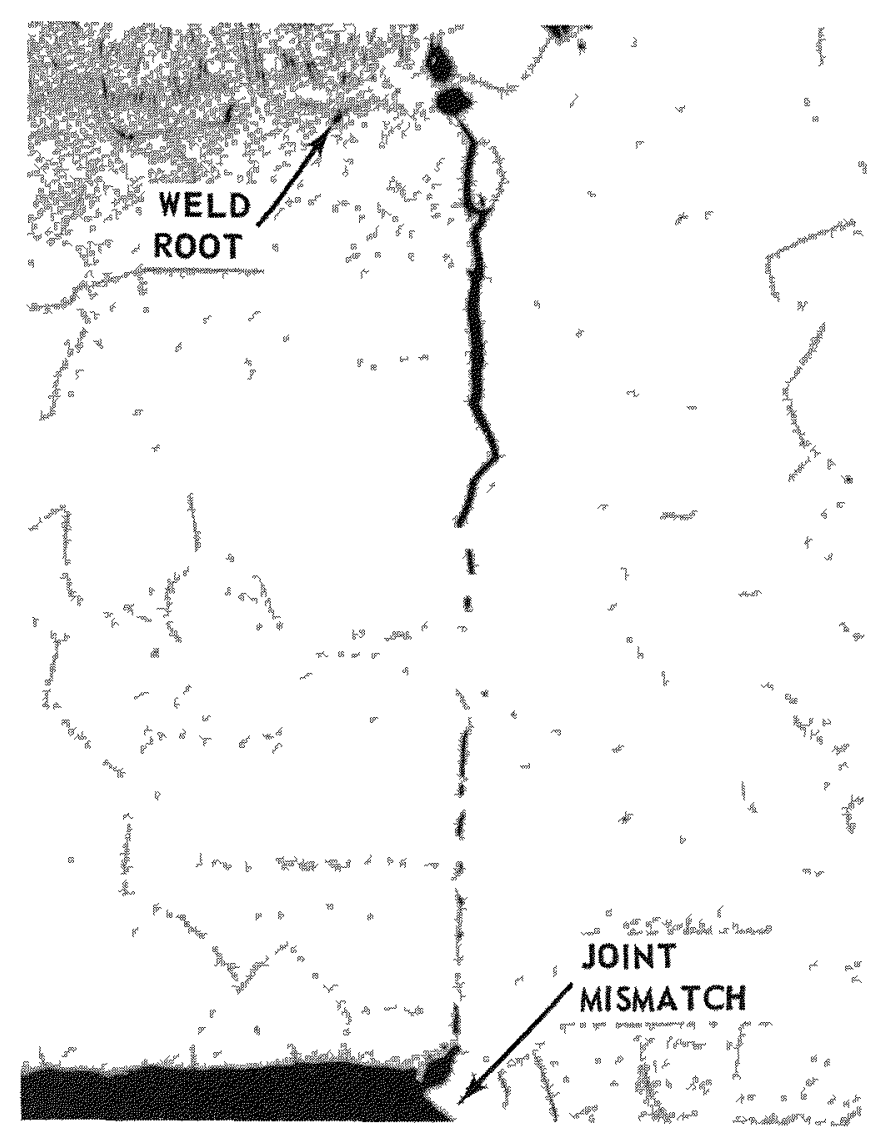

FIGURE 12 - Fifty percent weld penetration level (100X). 


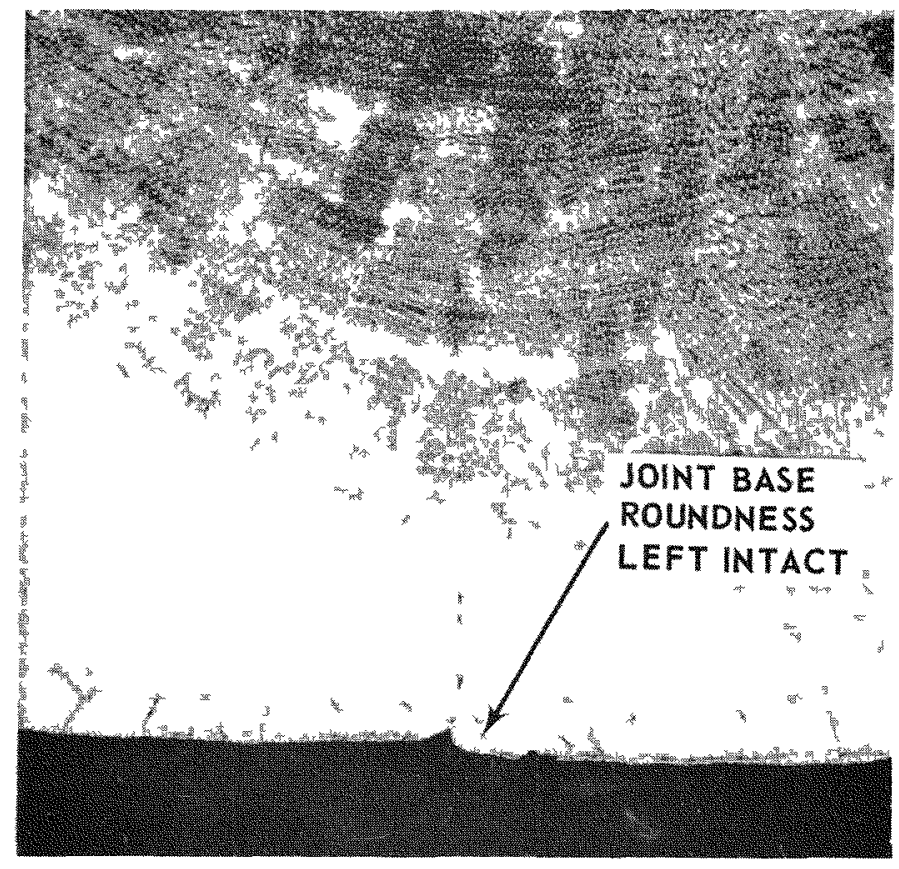

FIGURE 13 - Typical of weld transverse section a $75 \%$ weld penetration level ( $40 X)$.

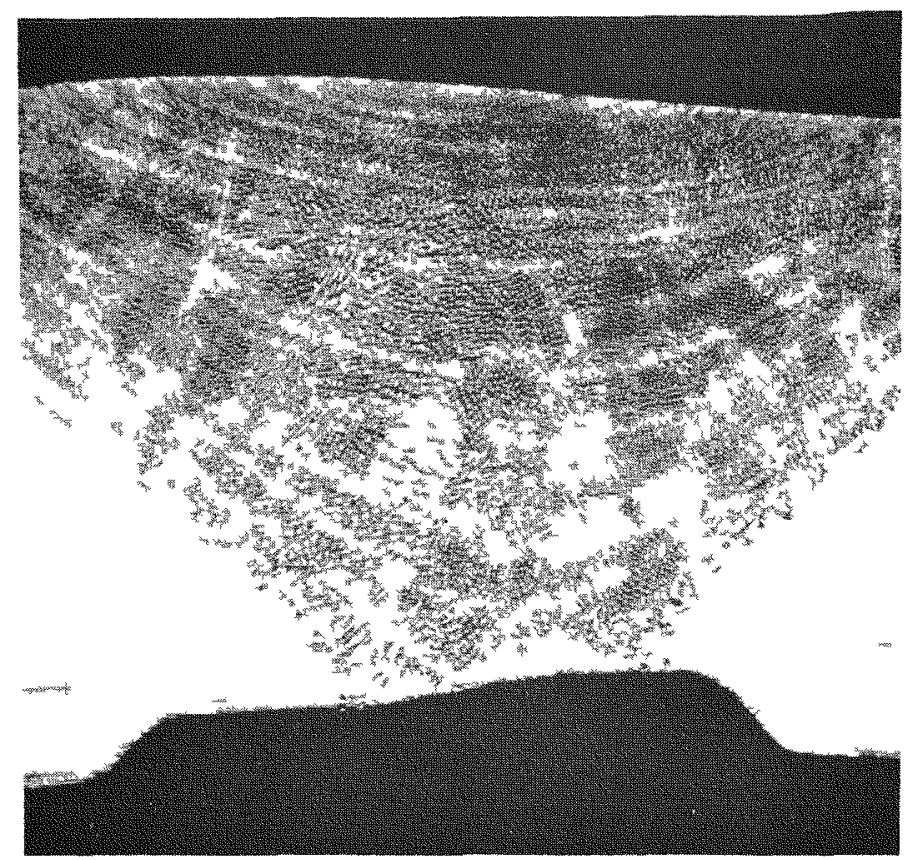

FIGURE 14 - Typical transverse section of fully penetrated regions of control welds (30X). 
and 5 mil eloxed slots in the weld standard. Similar LOP results were obtained for the two under-welded control units at the nominal 25\% penetration level.

At higher levels of weld penetration, no indications of LOP were detected ultrasonically. Figure 13 is a photomicrograph of a production example weld where LOP was indicated as probable from radiographic inspection. Although the weld shown in Figure 13 was not examined ultrasonically, it does typify what was observed destructively at the 75 \% penetration level for the control welds. The weld cross section in Figure 13 clearly shows the unwelded portion of the joint to be completely diffusion bonded with only the base corner roundness of the joint left intact as an acceptable condition. If this particular weld had been inspected ultrasonically, the signal strength would have been less than that obtained from the $2 \mathrm{mil}$ slot in the weld standard. Figure 14 represents the typical weld cross section of the fully penetrated regions of the control welds and is typical of production welds.

Conclusions Resulting from the Development Effort Based upon the results obtained from applying the ultrasonic technique to various control welds and production example welds, the following conclusions were drawn:

a) That the ultrasonic technique was applicable to inspection of fueled assemblies.

b) That LOP exceeding 25\% in welds was considered extremely remote in quality hardware.

c) That LOP of less than 25\% might erroneously occur in welds but would be acceptable and undetectable ultrasonically.

Results of Applying the Ultrasonic Inspection Technique to Product Assemblies Even though the results from the ultrasonic development effort indicated that the welding process is suffuciently controlled to the extent that there is little chance of LOP occurring in a weld, it was decided to incorporate the test to provide additional NDT assurance of weld quality. The ultrasonic test procedure has been used in more than 50 non-fueled impact test assemblies and the first seven fueled assemblies. For these items, no indication of detectable LOP was ever indicated.

\section{CONCLUSIONS}

In summary, what is described in this report is the development of an ultrasonic technique to permit nondestructive inspection of a critical weld for containing large amounts of plutonium-238 for space applications. Results of the ultrasonic technique showed the approach to be superior to radiography in detecting a condition of unacceptable LOP. For the control welds used in the ultrasonic development effort, LOP was detectable at weld penetration levels of $50 \%$ and less. For higher penetration levels, LOP was not detectable by the ultrasonic technique (a result of the unwelded portion of the joint being diffusion bonded). Even though no detectable LOP was expected to occur in fueled heat source welds, the ultrasonic inspection was applied to the first seven sources as added assurance of weld quality. And indeed, no LOP was detected in these seven units. 